\title{
ATORVASTATIN INDUCED ACUTE PANCREATITIS? - A RARE CASE REPORT
}

\author{
JAIDEV KUMAR*, ASHOKA, RAKSHITH, UMESH
}

Department of Pharmacy Practice, JSS College of Pharmacy, JSS Academy of Higher Education and Research, Mysuru, Karnataka, India. Email: brjayadevkumar@jssuni.edu.in.

Received: 02 June 2019, Revised and Accepted: 06 August 2019

ABSTRACT

Acute pancreatitis is a clinical condition characterized by inflammation of pancreas. The specific time interval to suspect any patient as acute pancreatitis is not clearly defined in any therapeutic guideline and usually symptoms will be lasted for a short period of time. The management of acute pancreatitis always depends on underlying cause. The common medications that can cause acute pancreatitis include angiotensin-converting enzyme inhibitors, azathioprine, and pentamidine. According to the patient case history, abdominal pain was on and off; the patient also received nonsteroidal anti-inflammatory drugs, i.e., tablet aceclofenac $100 \mathrm{mg}$ for abdominal pain, whenever he was experiencing pain and it got subsided only for short period of time. This case report did not have clear subjective and objective evidence to suspect atorvastatin which was the main culprit of causing acute pancreatitis. The incidence of causing drug-induced acute pancreatitis is very low which was accountable for only $0.1-2 \%$. This case report concludes that all health-care professionals needs to have close monitoring of atorvastatin causing acute pancreatitis which is very rarely seen.

Keywords: Acute pancreatitis, Atorvastatin, Abdominal pain, Rare

(C) 2019 The Authors. Published by Innovare Academic Sciences Pvt Ltd. This is an open access article under the CC BY license (http://creativecommons. org/licenses/by/4. 0/) DOI: http://dx.doi.org/10.22159/ajpcr.2019.v12i10.34417

\section{INTRODUCTION}

Acute pancreatitis is a clinical condition characterized by inflammation of pancreas. The specific time interval to suspect any patient as acute pancreatitis is not clearly defined in any therapeutic guideline and usually symptoms will be lasted for a short period of time [1-3]. The management of acute pancreatitis always depends on underlying cause. The common causes of acute pancreatitis are gall stones, ethyl alcohol abuse, and hyperparathyroidism, viruses such as mumps and cytomegalovirus, hyperlipidemia, injury to the pancreas occurred during surgery, pancreatic cancer, hereditary pancreas seen among patients with cystic fibrosis genes, cigarette smoking, and kidney transplantation [4,5]. The common medications that can cause acute pancreatitis include:

- Angiotensin-converting enzyme (ACE) inhibitors

- Azathioprine

- 6-mercaptopurine

- Pentamidine

- Cotrimoxazole

- Valproic acid

- Any women receiving estrogen-containing medications with high level of lipids in the blood.

Statins induced pancreatitis is very rare, there are case reports of causing pancreatitis among statins are atorvastatin, fluvastatin, rosuvastatin, simvastatin, and pravastatin. The probable mechanism of causing statins induced pancreatitis is as follows:

- Immune-mediated inflammatory response

- Direct cellular toxicity

- Metabolic effect.

However, there is no clear evidence of any of these three mechanisms which are held responsible of causing pancreatitis by statins [6].

As per the evidence found with regarding to drug induced pancreatititis causing incidence was $0.1-02 \%$, however true incidence of causing drug-induced pancreatitis is lacking due to insufficient clinical evidence.

Common clinical manifestations that are associated with acute pancreatitis include upper abdominal pain which is radiating to the back, followed by nausea and vomiting, coughing, and rapid breathing.
Especially, the intensity of abdominal pain will vary depending on the cause. Untreated acute pancreatitis can lead to complications such as hypotension and shock, followed by damage to other organs, infection of the pancreas, and pancreatic pseudocyst [7]

\section{CASE REPORT}

This is the case of a 60-year-old male with known case of hypertension; type II diabetes mellitus since 10 years was prescribed with following medications such as tablet hydrochlorothiazide $12.5 \mathrm{mg}$ once in every $12 \mathrm{~h}$, followed by tablet amlodipine $5 \mathrm{mg}$ once in every $12 \mathrm{~h}$, tablet metformin $500 \mathrm{mg}$ once in every $12 \mathrm{~h}$, and tablet glimepiride $2 \mathrm{mg}$ once in every $24 \mathrm{~h}$ and tablet atorvastatin $20 \mathrm{mg}$ once in every $24 \mathrm{~h}$ only during night time. The patient allergic history of medications is nil known allergy. The patient family allergic history of medications was father allergic to benzathine penicillin. The patient was hospitalized in tertiary care hospital due to uncontrolled blood pressure and blood sugar which had resulted diabetic nephropathy. Diabetic nephropathy was aggressively treated with ACE inhibitors such as injection enalapril $2.5 \mathrm{mg}$ once in every $24 \mathrm{~h}$ combined with injection furosemide $40 \mathrm{mg}$ once in every $12 \mathrm{~h}$. Tablet atorvastatin $20 \mathrm{mg}$ was administered once in every $24 \mathrm{~h}$ during hospital stay. The laboratory investigations such as serum creatinine, serum blood urea nitrogen, and all electrolytes were monitored from the day one of hospitalisation till patient got discharged. Once parenteral therapy was initiated, the patient clinical condition was stable. The dose of prescribed drugs was complying in according to creatinine clearance of the patient. The body weight and serum creatinine were $56 \mathrm{Kg}$ and $2.3 \mathrm{mg} / \mathrm{dl}$ (normal serum creatinine was $0.8-1.4 \mathrm{mg} / \mathrm{dl}$ ). General physician who was treating this medical case had directed to undergo following investigations such as complete blood count, fasting blood sugar (FBS), postprandial blood sugar (PPBS), liver function tests (LFTs), electrolytes sodium, potassium, chloride, serum creatinine, serum blood urea nitrogen, and glycosylated hemoglobin on the day of admission. Serum creatinine was found to be $2.3 \mathrm{mg} / \mathrm{dl}$ followed by FBS - $185 \mathrm{mg} / \mathrm{dl}$ and PPBS $-278 \mathrm{mg} / \mathrm{dl}$, while the rest of the other investigations were found to be normal.

\section{DISCUSSION}

Drugs that are suspected to cause pancreatitis should only be confirmed by dechallenging as most of the research investigators have been 
suggested in according to their clinical experience [8]. The rechallenge test is the best indicator to assess any offending drug is responsible to cause pancreatitis, but at the same time, it cannot be applied to the patient with severe pancreatitis which was expressed by experienced research investigators [9]. Statins causing pancreatitis very rare which had been seen among these medications such as atorvastatin, fluvastatin, and rosuvastatin due to class effect. Statin medications causing pancreatitis may be associated with extent of lipophilicity and those which have ability to inhibit cytochrome P450 CYPA4 as expressed by few research investigators $[10,11]$

During hospitalization, the patient was prescribed with the following medications:

\begin{tabular}{|c|c|c|c|c|}
\hline $\begin{array}{l}\text { S. } \\
\text { No. }\end{array}$ & $\begin{array}{l}\text { Name of the } \\
\text { medication }\end{array}$ & $\begin{array}{l}\text { Frequency of } \\
\text { administration }\end{array}$ & $\begin{array}{l}\text { Route of } \\
\text { administration }\end{array}$ & $\begin{array}{l}\text { Dose of } \\
\text { medication }\end{array}$ \\
\hline 1. & $\begin{array}{l}\text { Human } \\
\text { actrapid }\end{array}$ & $1-1-1$ & IV & $25-25-25$ units \\
\hline 2. & Inj. enalapril & $1-0-1$ & IV & $5 \mathrm{mg}-0-5 \mathrm{mg}$ \\
\hline 3. & Inj. ceftriaxone & $1-0-1$ & IV & $1 \mathrm{~g}$ \\
\hline 4. & $\begin{array}{l}\text { Tablet } \\
\text { pantoprazole }\end{array}$ & SoS & Oral & $40 \mathrm{mg}$ \\
\hline 5. & $\begin{array}{l}\text { Tablet } \\
\text { atorvastatin }\end{array}$ & $0-0-1$ & Oral & $20 \mathrm{mg}$ \\
\hline
\end{tabular}

The patient was responding well to all the medications from day 1 to day 5 . However, suddenly, the patient had complained of abdominal pain with shortness of breath on day 6 onward. Patient consultant had referred this case to surgeon for further review of this medical case. Surgeon after reviewing this case ruled out appendicitis, cholelithiasis, and gallstones, but it was suspected with acute pancreatitis due to abdominal pain that is persisting in the patient. Surgeon had prescribed tablet paracetamol $325 \mathrm{mg}$ + tramadol $37.5 \mathrm{mg}$ for abdominal pain.

According to the patient case history, abdominal pain was on and off; the patient also received nonsteroidal anti-inflammatory drugs, i.e., tablet aceclofenac $100 \mathrm{mg}$ for abdominal pain, whenever he was experiencing pain and it got subsided only for short period. This abdominal pain was persisting for the past 4 months in this medical case, but the patient did not bring into the notice of concerned consultant with respect to abdominal pain, whenever the patient was undergoing medical follow-up. The patient concerned consultant thought, is there any medications that can cause abdominal pain and acute pancreatitis among the prescription. However, the patient gives safe medication history of all the prescribed medications. Among the prescribed medications, enalapril and atorvastatin are the only medications that can cause acute pancreatitis, but time temporal relationship for enalapril and atorvastatin in literature review was not known till today. Finally, the patient consultant had directed to undergo investigations of enzymes of lipase and amylase, calcium, and LFTs where enzyme lipase was found to be $250 \mathrm{U} / \mathrm{L}$ (normal range 16-63 U/L), followed by enzyme amylase $150 \mathrm{U} / \mathrm{L}$ (normal range 20-104 U/L) while rest of the other investigations such as calcium and LFTs were found to be within normal limits. Endoscopic ultrasound was also done in this medical case to rule out any obstructive possibilities such as tumors of pancreas head, and endoscopic ultrasound report was found to be normal without showing any pancreatic complications.

According to older research study, statin-induced pancreatitis may have time temporal relationship from hours to years after treatment [1]. The possible mechanism of causing statins induced pancreatitis is:

- Direct toxic effect to the pancreas and accumulation of toxic metabolite.
- Speculated to be associated with rhabdomyolysis, myalgia, or metabolism or drug interactions through cytochrome P-450 3A4 (CYP3A4) [1].

\section{CONCLUSION}

This case report did not have clear subjective and objective evidence to suspect atorvastatin which was the main culprit of causing acute pancreatitis. Abdominal pain on and off of the patient was the one where clinician had suspected acute pancreatitis, where they even ruled out gallstones and pancreatic tumor in this medical case. The patient was finally suggested to dechallenge suspected atorvastatin for a short period of time and asked to observe whether abdominal pain completely subsides. However, the patient was not able to recognize abdominal pain while undergoing atorvastatin therapy since it was on and off. The incidence of causing drug-induced acute pancreatitis is very low which was accountable for only $0.1-2 \%$. This case report concludes that all health-care professionals needs to have close monitoring among patients undergoing atorvastatin therapy.

\section{CONFLICT OF INTERSET}

None.

\section{AUTHORS CONTRIBUTION}

All authors have equally contributed for making this case report to be successful.

\section{REFERENCES}

1. Jones MR, Hall OM, Kaye AM, Kaye AD. Drug-induced acute pancreatitis: A review. Ochsner J 2015;15:45-51.

2. Vege SS, Yadav D, Chari ST. Pancreatitis. In: Talley NJ, Locke GR, Saito YA, editors. GI Epidemiology. Malden, MA: Blackwell Publishing; 2007.

3. McArthur KE. Review article: Drug-induced pancreatitis. Aliment Pharmacol Ther 1996;10:23-38.

4. Peery AF, Dellon ES, Lund J, Crockett SD, McGowan CE, Bulsiewicz WJ, et al. Burden of gastrointestinal disease in the United States: 2012 update. Gastroenterology 2012;143:1179-87000.

5. Bradley EL $3^{\text {rd }}$. A clinically based classification system for acute pancreatitis. Summary of the international symposium on acute pancreatitis, atlanta, ga, september 11 through 13, 1992. Arch Surg 1993;128:586-90.

6. Dervenis C, Johnson CD, Bassi C, Bradley E, Imrie CW, McMahon MJ, et al. Diagnosis, objective assessment of severity, and management of acute pancreatitis. Santorini consensus conference. Int J Pancreatol 1999;25:195-210.

7. Kitamoto Y, Yuan X, Wu Q, McCourt DW, Sadler JE. Enterokinase, the initiator of intestinal digestion, is a mosaic protease composed of a distinctive assortment of domains. Proc Natl Acad Sci U S A 1994;91:7588-92.

8. Yamashina I. The action of enterokinase on trypsinogen. Biochim Biophys Acta 1956;20:433-4

9. Aoun E, Chang CC, Greer JB, Papachristou GI, Barmada MM, Whitcomb DC, et al. Pathways to injury in chronic pancreatitis: Decoding the role of the high-risk SPINK1 N34S haplotype using meta-analysis. PLoS One 2008;3:e2003.

10. Rowntree RK, Harris A. The phenotypic consequences of CFTR mutations. Ann Hum Genet 2003;67:471-85.

11. Forsmark CE, Baillie J, AGA Institute Clinical Practice and Economics Committee, AGA Institute Governing Board. AGA institute technical review on acute pancreatitis. Gastroenterology 2007;132:2022-44. 